\title{
EVALUATION OF TOXICITY PROFILES OF DIFFERENT BRANDS OF PIROXICAM IN WISTAR RATS
}

\author{
Lemii, B. Cletus $^{1}{ }^{凶}$ and Onwunari, A. Georgewill ${ }^{2}$ \\ ${ }^{1}$ Department of Pharmacology and Therapeutics, Faculty of Basic Medical Sciences, College of Medical Sciences Rivers \\ State University Port Harcourt, Nigeria \\ ${ }^{2}$ Department of pharmacology, Faculty of Basic Clinical Sciences, College of Health Sciences University of Port Harcourt, \\ Nigeria
}
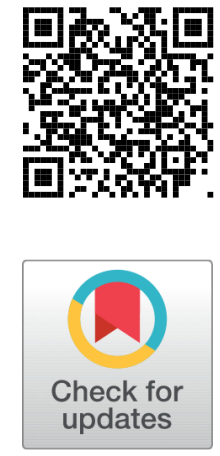

Received 1 June 2021

Accepted 15 June 2021

Published 30 June 2021

Corresponding Author

Lemii, B. Cletus, cletus.lemii@ust.e du.ng

DOI 10.29121/

granthaalayah.v9.i6.2021.3975

Funding: This research received no specific grant from any funding agency in the public, commercial, or not-for-profit sectors.

Copyright: (C) 2021 The Author(s). This is an open access article distributed under the terms of the Creative Commons Attribution License, which permits unrestricted use, distribution, and reproduction in any medium, provided the original author and source are credited.

OPEN ACCESS

\section{ABSTRACT}

BACKGROUD: Piroxicam, a non-steroidal anti-inflammatory drug (NSAID), has been identified to be one of such drugs with great potentials for abuse, addiction and death as well as complaints on the significant dissimilarities and variations of possible organ toxicities across different brands. This study aimed at evaluating toxicity profiles of different brands of Piroxicam in male Wistar rats. Healthy thirty (30) male Wistar rats, weighing between 180 and 230grams were procured from the animal house of the Pharmacology department, Faculty of Basic Clinical Sciences in University of Port Harcourt, Nigeria.

METHODS: The animals were divided into six (6) groups of five (5) animals each. Group1-control group while group2 to 6 were treatment groups. Thereafter, the clinical dose $(0.285 \mathrm{mg} / \mathrm{kg})$ of Piroxicam brands (A Brand, B Brand, C Brand, D Brand and E Brand) were administered on treatment groups. The histopathological analysis was done at the end of the experiment.

RESULT: Reveals that, four out of the fives Piroxicam brands demonstrated significant $(\mathrm{p}<0.05)$ histopathological toxicities on liver and kidney. Two of the brands has predilection for liver toxicity while another two exhibited kidney toxicities. The heart organ was spared from toxic effects of all the five brand understudied.

CONCLUSION: The degree of organ toxicities with different brands of piroxicam varies, however, certain brands tend to have toxicity predilection for either the liver or kidney.

Keywords: Toxicity, Different Brands of Piroxicam

\section{INTRODUCTION}

Non-steroidal anti-inflammatory drugs (NSAIDS), a class of drugs within which Piroxicam falls, is among drugs most widely misused and with high potentials for 
abuse, addiction and death Wale (2015), Awodele et al. (2015). A case-control study done on the population of southern Italy estimating the relationship between the use of individual NSAIDS and their relative risk on chronic renal disease (CRD), testified that the risk differs among different NSAIDS. Continuous administration of Oxicams especially piroxicam and meloxicam precipitated subclinical CRD Ingrasciotta et al. (2015)

Many studies on NSAIDS and particularly few long-term studies done on the histopathological changes/effects of piroxicam on the liver and kidney had shown remarkable pathological changes Ebaid et al. (2007), Omar (2018). Acute studies on histopathological effect of piroxicam on these major organs including the heart are rare. Expenditure on a generic drug increases as new brands are introduced Sarpatwari et al. (2019). Equally piroxicam being an NSAIDS with a single daily regimen, compliance and possible potential for abuse with consequent acute effect on organs of metabolism (liver and kidney) and major cardiovascular organ, the heart is possible and thus necessitated this study. Comparison of differences in side effects of commercially available multiple brands of piroxcam are also not readily reached.

\section{METHOD}

\subsection{RESEARCH DESIGN}

This study was a laboratory experimental animal-based study;

All the study animals were handled according to National Institute of Health (NIH) guidelines for use and care of animals.

\subsection{EXPERIMENTAL ANIMAL PREPARATION}

Thirty (30) healthy male Wistar rats, weighing between 180 and 230grams were procured and housed in the animal house unit of the Department of Pharmacology, University of Port Harcourt, Nigeria. The animals were acclimatized for two weeks at ambient temperature of 12 hours' light and dark cycle and were fed with pellets growers and normal tap water ad libitum. Ethical approval was granted post application from the research and ethical committee of the University of Port Harcourt. Reference number: UPH/CEREMAD/REC/MM74/004. All the study animals were handled according to National Institute of Health (NIH) guidelines for care and use of experimental laboratory animals "NRC [National Research Council]" (2017).

\subsection{GENERAL EXPERIMENTAL PROTOCOL}

The animals were divided into six (6) different groups of 5 rats each for each phase

Group 1-- control (induced but not treated)

Group 2--(A brand of Piroxicam) treatment group

Group 3- (B brand of Piroxicam) treatment group

Group4 - (C brand of Piroxicam) treatment group 


\section{Group 5-(D brand of Piroxicam) treatment group \\ Group 6-- (E brand of Piroxicam) treatment group}

\section{METHOD}

The animals were prepared and care for according to the NRC, 2017 guidelines.Clinical dose $(0.285 \mathrm{mg} / \mathrm{kg})$ of the stated Piroxicam brands were administered intraperitoneally to the different groups except the control group and allowed for four hours. Thereafter, the animals were sedated using $80 \%$ trichloromethane (chloroform) and the liver, kidneys and heart were obtained for laboratory analysis for any possible toxicity

\section{TISSUE PREPARATION}

The tissues were fixed with $10 \%$ formalin for 48 hours and then transferred to labelled tissue cassettes where it was stored with formalin before processing. The stored tissues were immersed in increasing concentrations of alcohol in order to dehydrate, cleared with xylene. They were then embedded with paraffin molten to create a block before sectioning and subsequent staining.

\section{ANALYSIS OF TOXICITY PROFILES OF DIFFERENT BRANDS OF PIROXICAM IN WISTAR RATS}

Normal liver with portal traids- normal hepatocytes, normal sinusoids and capillaries for $\mathrm{C}$ Brand as demonstrated by normal liver histology in Plate 1 below

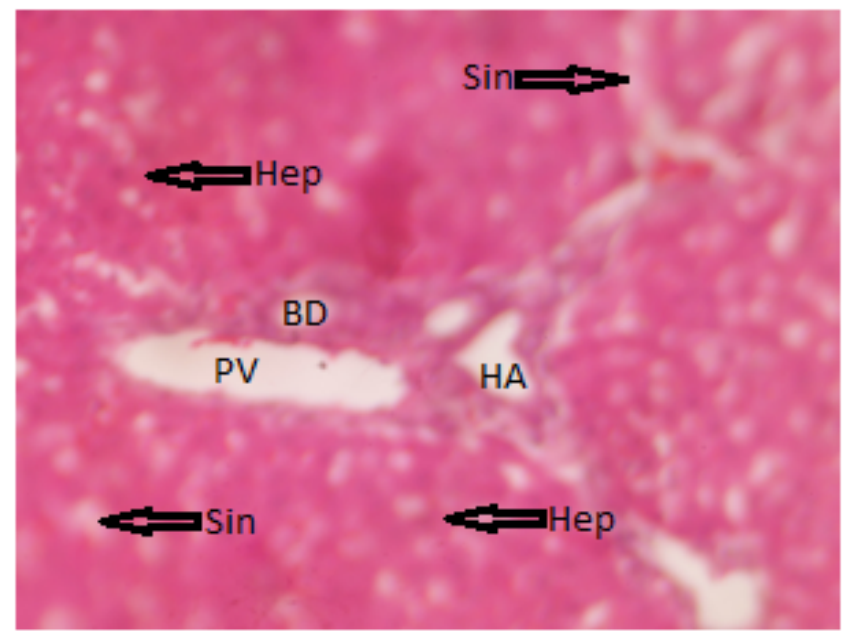

2045

Plate 1: Photomicrograph of Liver- $(0.285 \mathrm{mg} / \mathrm{kg}$ of C Brand) (H \& E) (X400): Histologically normal liver, showing: (1) patent portal triads (Hepatic artery HA; Portal vein PV; bile duct BD). (2) Normal hepatocytes (Hep), (3) sinusoids (Sin) 
Normal liver with portal traids- normal hepatocytes, normal sinusoids and capillaries for Control group as shown by normal liver histology in Plate 2 below

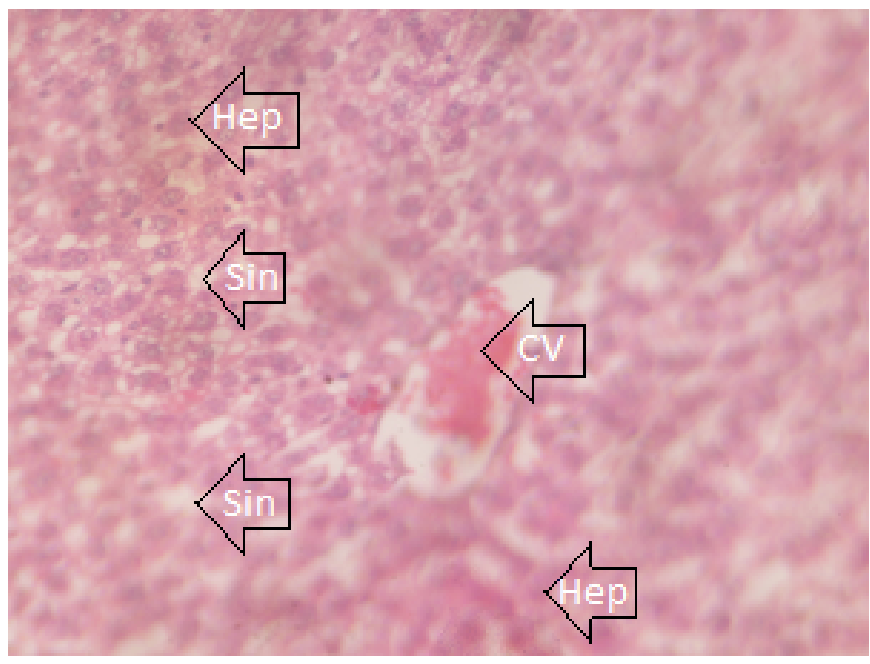

2047

Plate 2: Photomicrograph of Liver- $(0.285 \mathrm{mg} / \mathrm{kg}$ of control group) (H \& E) (X400): Histologically normal liver, showing (1) congested central vein (CV), (2) Normal hepatocytes (Hep), (3) sinusoids (sin) containing capillaries

Plate 3 below shows histologically normal kidneys indicating the intact glomerulus (containing glomerular cells, glomerular capillaries and mesangial cells), normal Bowman's capsule and renal tubules for the control group.

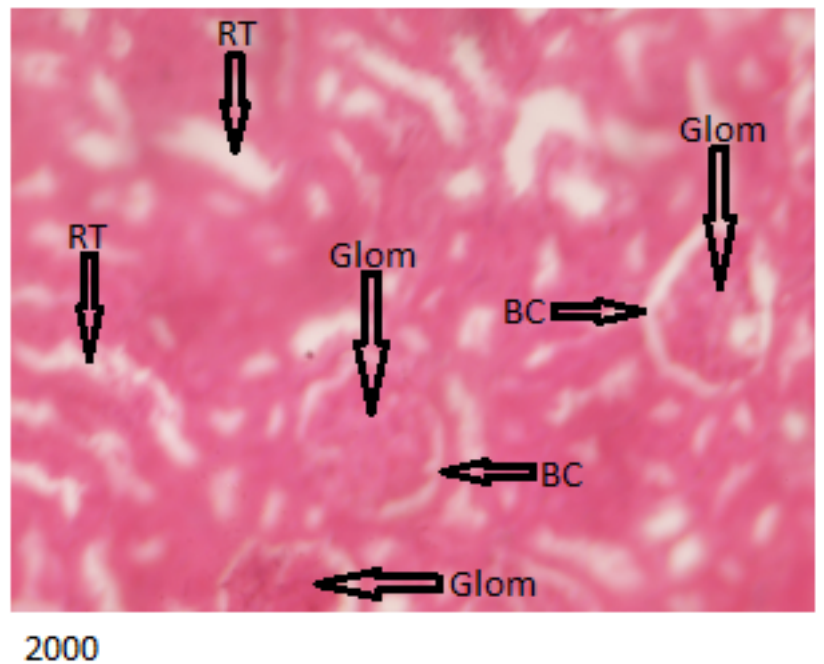

Plate 3: Histologicallynormal kidney. $\quad(0.285 \mathrm{mg} / \mathrm{kg}$ of control group) (H \& E) (X400): (1) Glomerulus (Glom) containing glomerular cells, glomerular capillaries and mesangial matrix. (2) Bowman's capsular space (BC), (3) Renal tubules (RT) 
The E Brand treated group below in Plate 4 showed kidneys with histological distortions and occluded Bowman's capsular space with lobulation of the glomerulus.

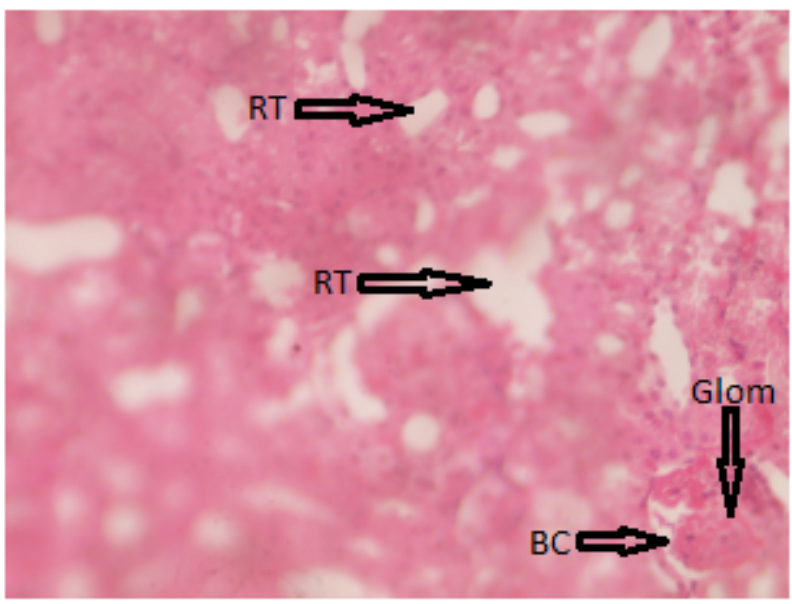

2014

Plate 4: Photomicrograph of Kidney- $(0.285 \mathrm{mg} / \mathrm{kg}$ of E Brand) (H \& E) (X400): Histologically distorted kidney (mild distortion), showing (1) obliterated Bowman's capsular space (BC) with normal renal tubules (RT)

The B Brand treated group showed histologically distorted liver with congested central vein and microvesicular steatosis as demonstrated below in Plate 5 .

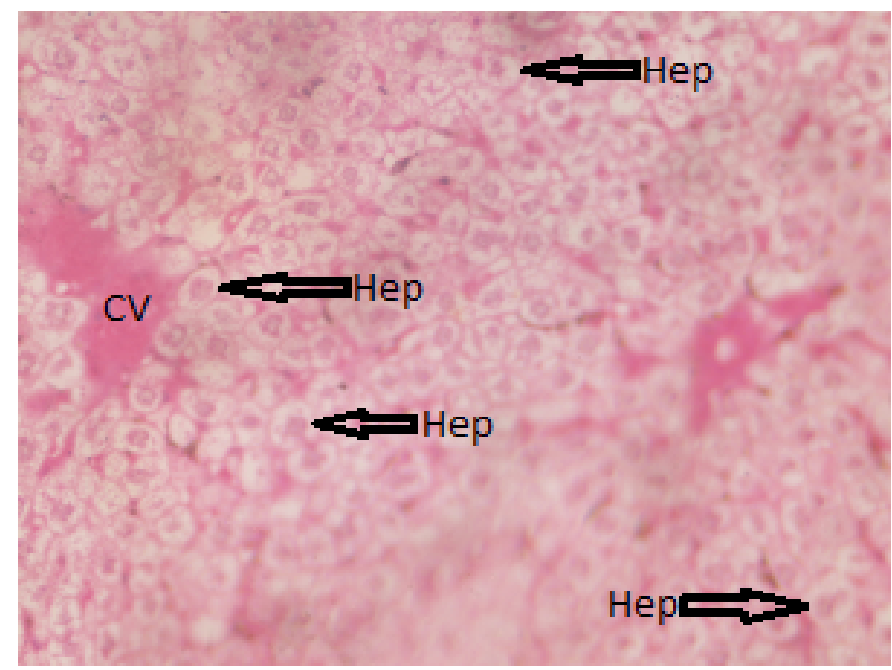

\section{6}

Plate 5: Photomicrograph of Liver- $(0.285 \mathrm{mg} / \mathrm{kg}$ of B Brand) (H \& E) (X400). Histologically distorted liver, showing (1) hepatocytes (Hep) with microvesicular steartosis, (2) congested central vein (cv).

The E Brand treated group showed histologically distorted kidney revealing occluded Bowman capsule as shown below in Plate 6 . 


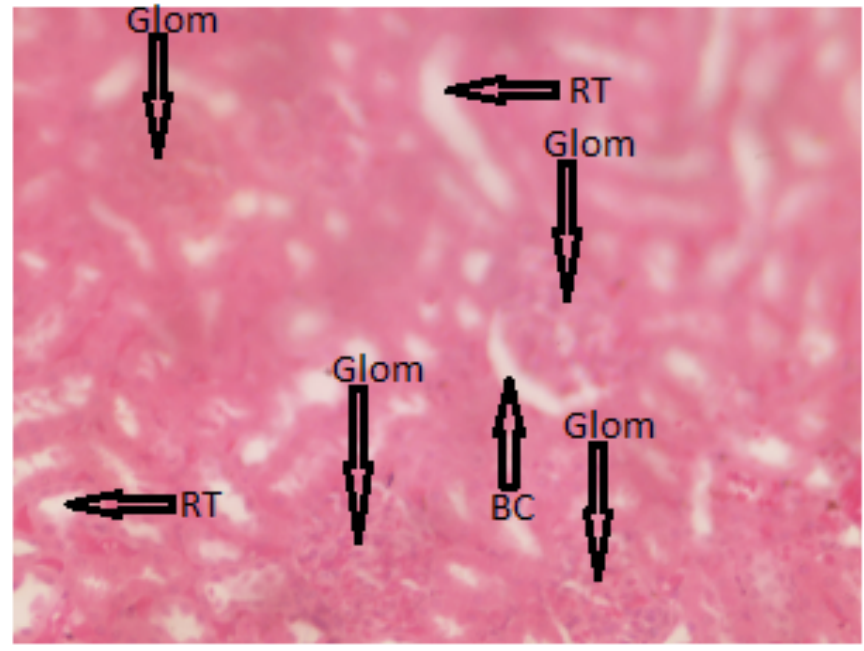

2032

Plate 6: Photomicrograph of Kidney- $(0.285 \mathrm{mg} / \mathrm{kg}$ of E Brand) (H \& E) (X400): Histologically mildly distorted kidney, showing Occluded Bowman's capsular space (BC).

The D Brand treated group which indicated distorted liver histology with microvesicular steartosis and congested central vein as shown in Plate 7 below.

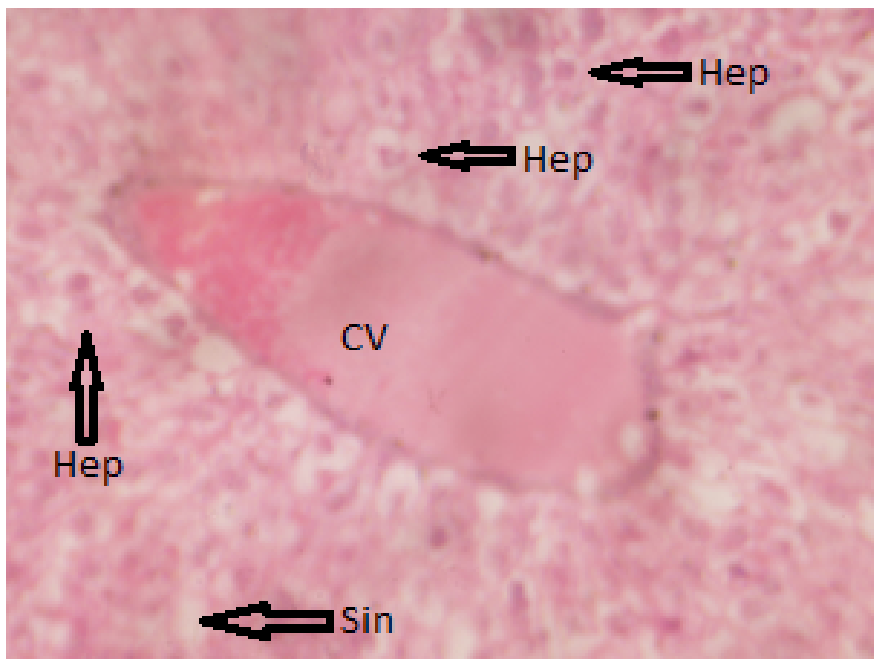

2064

Plate 7: Photomicrograph of Liver- $(0.285 \mathrm{mg} / \mathrm{kg}$ of D Brand) (H \& E) (X400): Histologically distorted liver, showing (1) congested central vein (CV) (2) hepatocytes (Hep) with microvesicular steartosis, (3) sinusoids ( $\sin$ )

The histology of the kidney in a rat A Brand treated group which indicated distorted kidney histology (Plate 8 ) 


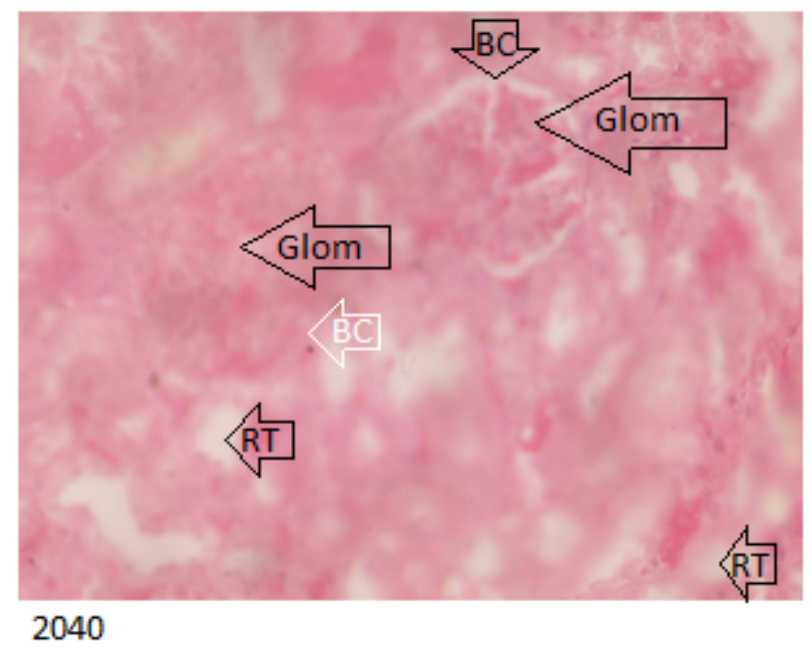

Plate 8: Photomicrograph of Kidney- $(0.285 \mathrm{mg} / \mathrm{kg}$ of A Brand) (H \& E) (X400): Histologically mildly distorted kidney, showing OccludedBowman's capsular space (BC),

The result of the cardiac muscle evaluation of the toxicity profile of different brands of Piroxicam in all treatment groups and control showed histologically normal cardiac muscle fibers showing normal cardiac myofibrils that are homogeneous, branched, weaved and merged with each other forming a continuous syncytium and centrally located nuclei as indicated in Plate 9 below.

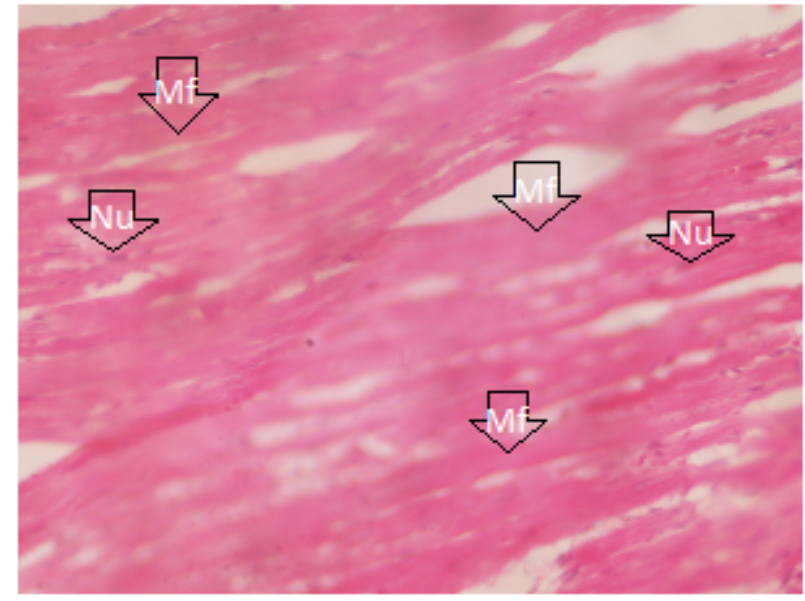

2069

Plate 9: Histologically normal heart $(0.285 \mathrm{mg} / \mathrm{kg}$ of different piroxicam brands \& control group) (H \& E) (X400): Histologically normal cardiac muscle showing (1) Cardiac myofibrils fibers (Mf) that are homogenous in diameter, polygonal in shape with intact sarcolemma (2) centrally located nuclei $(\mathrm{Nu})$ 


\section{DISCUSSION}

The photomicrographs of the kidney histology of rats treated with C Brand and controls were normal indicating that the $\mathrm{C}$ Brand of piroxicam must have impacted less or no toxic effects on the kidney. However, the kidney of rat treated with A Brand and E Brand groups indicated distorted histology with occluded Bowman's capsule space and lobulations of the glomerulus. The degree and frequency of the hepatic histopathology were more for E Brand treated group than the A Brand treated group. The kidney been the lead organ in drug metabolism, may be predisposed to toxic injury of piroxicam at therapeutic doses and may cause an injury to the organ and thus inducing hepatotoxicity Sahu (2016). Scholars like Ebaid et al. (2007) \& Modi et al. (2012) also reported kidney sections of rats treated with Piroxicam showing inflammatory cellular infiltration, glomerular shrukening and vacuolations of tubular cells. Also, individual NSAIDS and their relative risk on chronic renal disease (CRD), proved that the risk differs among different NSAIDS and protracted exposure of Oxicams especially piroxicam and meloxicam precipitated subclinical CRD Ingrasciotta et al. (2015). It therefore reaffirmed need for caution when piroxicam would be use for long-term therapy or in those with renal pathology/ elderly

Thus, A Brand and E Brand brands may have possibly elicited injury in the kidney. This reminds us to exercise careful when recommending as Piroxicam brands as antiinflammatory anti-pyretic and as analgesic agents.

The photomicrographs of the kidney histology of rats treated with C Brand and controls were normal indicating that the $\mathrm{C}$ Brand of piroxicam must have impacted less or no toxic effects on the kidney. However, the result of the screening of the toxicity profile of the different brand of piroxicam on the kidney disclosed photomicrographs of abnormal liver histology in B Brand and D Brand treated animals. This might be due the role of this organ in piroxicam metabolism. According to Wang and Jiao (2000), drugs are capable of inducing oxidative stress via the production of free radicals due to their metabolism. Sahu (2016) had also reported that piroxicam at therapeutic doses may cause an injury to the organ and thus inducing hepatotoxicity. It therefore reaffirmed need for caution when piroxicam is use for long-term therapy or in those with renal pathology/ elderly.

It is of note that the myocardial fibres in all treated and control groups in this study demonstrated normal heart histology. This is possibly due to the noninvolvement of the heart organ in metabolism of piroxicam and therefore demonstrated possible less or non-toxicity of piroxicam on the heart.

\section{CONCLUSION}

The result of the toxicity profile screening of the photomicrographs of the different piroxicam brands treatment groups in Wistar rats in the present study showed that the photomicrographs of the kidney histology of rats treated with A Brand and E Brand brands showed distorted kidney with occluded Bowman's capsule space 
and glomerular lobulations while the photomicrographs of E and Brands showed histologically distorted liver, with congested central, abnormal hepatocytes with microvesicular steartosis and sinusoids. The histology of all the animals treated with the different brands of Piroxicam and control group had normal myocardial fibres.

Therefore, the present study had shown that the different brands of piroxicam (A Brand, B Brand, C Brand, D Brand and E Brand) understudied, possessed remarkable and variations in their degree and predilection of organ toxicities.

\section{REFERENCES}

Awodele, O., Fadipe, A. O., Adekoya, M., \& Adeyemi, 0. 0. (2015). Prescribing Pattern of NonSteroidal Ant-inflammatory Drugs at the Outpatient Pharmacy Department of Lagos University Teaching Hospital, Nigeria. Ghana Medical Journal, 49(1), 25-25. Retrieved from https://dx.doi.org/10.4314/gmj.v49i1.5 10.4314/gmj.v49i1.5

Ebaid, H., Dkhil, M. A., Danfour, M. A., Tohamy, A., \& Gabry, M. S. (2007). Piroxicam-Induced Hepatic And Renal Histopathological Changes In Mice. Libyan Journal Of Medicine, 2(2), 82-89.

Ingrasciotta, Y., Sultana, J., Giorgianni, F., Fontana, A., Santangelo, A., Tari, D. U., Santoro, D., Arcoraci, V., Perrotta, M., Ibanez, L., \& Trifirò, G. (2015). Association of Individual NonSteroidal Anti-Inflammatory Drugs and Chronic Kidney Disease: A Population-Based Case Control Study. PLOS ONE, 10(4), e0122899-e0122899. Retrieved from https:// dx.doi.org/10.1371/journal.pone.0122899 10.1371/journal.pone.0122899

Modi, C. M., Mody, S. K., Patel, H. B., Dudhatra, G. B., Kumar, A., \& Avale, M. (2012). Toxicopathological Overview Of Analgesic And Anti-Inflammatory Drugs In Animals. Journal Of Applied Pharmaceutical Science, 2(1), 149-157.

NRC [National Research Council]. (2017). Guidelines of The National Institute Of Health (NIH) For Care And Us of Laboratory/Research Animals [Accessed Online From: Retrieved from Https://Grants.Nih.Gov/Grants/Olaw/Guide-For-The-Care-And-Use -Of-Laboratory-Animals.Pdf

Omar, R. S. (2018). Piroxicam-Induced Hepatotoxicity. Biomed J Sci \&Tech Res, 2(3), 26012006.

Sahu, C. R. (2016). Mechanisms Involved in Toxicity of Liver Caused by Piroxicam in Mice and Protective Effects of Leaf Extract of Hibiscus Rosa-Sinensis L. Clinical Medicine Insights: Arthritis and Musculoskeletal Disorders, 9, CMAMD.S29463-CMAMD.S29463. Retrieved from https://dx.doi.org/10.4137/cmamd.s29463 10.4137/cmamd.s29463

Sarpatwari, A., DiBello, J., Zakarian, M., Najafzadeh, M., \& Kesselheim, A. S. (2019). Competition and price among brand-name drugs in the same class: A systematic review of the evidence. PLOS Medicine, 16(7), e1002872-e1002872. Retrieved from https:// dx.doi.org/10.1371/journal.pmed.1002872 10.1371/journal.pmed.1002872

Wale, D. (2015). Five Drugs Commonly Abused By Nigerians And Their Adverse Effects. Retrieved from Www.Nigerianbulletin,Com/Threads 13/4/2019

Wang, S. Y., \& Jiao, H. (2000). Scavenging Capacity of Berry Crops on Superoxide Radicals, Hydrogen Peroxide, Hydroxyl Radicals, and Singlet Oxygen. Journal of Agricultural and Food Chemistry, 48(11), 5677-5684. Retrieved from https://dx.doi.org/10.1021/ jf000766i 10.1021/jf000766i 